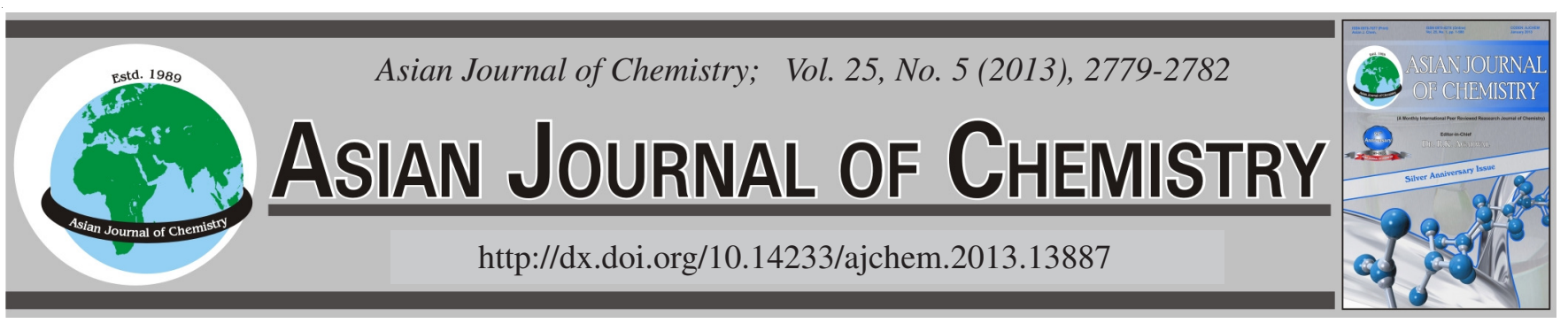

\title{
Kinetics and Mechanism of the Oxidation of DL-Methionine by Tetrakis(Pyridine)silver Dichromate
}

\author{
M. Patel ${ }^{1}$, L. Mathur ${ }^{1}$, K. Jha ${ }^{2}$, A. Kothari ${ }^{1}$, I. Shastri ${ }^{2}$ and Pradeep K. Sharma ${ }^{1, *}$
}

${ }^{1}$ Department of Chemistry, Jai Narain Vyas University, Jodhpur-342 005, India

${ }^{2}$ Department of Chemistry, R.D. National College, Mumbai-400 050, India

*Corresponding author: E-mail: drpkvs27@yahoo.com

(Received: 11 April 2012;

Accepted: 23 November 2012)

AJC-12453

\begin{abstract}
The oxidation of methionine by tetrakis(pyridine)silver dichromate in dimethyl sulphoxide leads to the formation of corresponding sulphoxide. The reaction is of first order with respect to tetrakis(pyridine)silver dichromate. Michaelis-Menten type kinetics was observed with respect to methionine. The reaction is catalyzed by hydrogen ions. The hydrogen-ion dependence has the form: $\mathrm{k}_{\mathrm{obs}}=\mathrm{a}+\mathrm{b}\left[\mathrm{H}^{+}\right]$. The oxidation of methionine was studied in 19 different organic solvents. The solvent effect was analyzed by Kamlet's and Swain's multiparametric equations. Solvent effect indicated the importance of the cation-solvating power of the solvent. A suitable mechanism has also been postulated.
\end{abstract}

Key Words: Dichromate, Kinetics, Mechanism, Methionine, Oxidation.

\section{INTRODUCTION}

$\mathrm{Cr}(\mathrm{VI})$ salts have long been used as oxidizing reagents in synthetic organic chemistry. However these salts are rather drastic in nature and non-selective oxidants. Further, they are insoluble in most of the organic solvents. Thus miscibility is a problem. To overcome these limitations, a large number of organic derivatives of $\mathrm{Cr}(\mathrm{VI})$ have been prepared and used in organic synthesis as mild and selective oxidants in non-aqueous solvents ${ }^{1}$. One of such compounds is tetrakis(pyridine)silver dichromate reported by Firozabadi et $a .^{2}$. We have been interested in the kinetic and mechanistic aspects of the oxidation by complex salts of $\mathrm{Cr}(\mathrm{VI})$ and several studies have already been reported from our laboratory ${ }^{3-6}$. It is, known however, that mode of oxidation depends upon the nature of counter-ion attached to the chromium anion. Methionine (Met), a sulphurcontaining optically active essential amino acid, is reported to behave differently from other amino acids, towards many oxidants $^{7,8}$, due to electron-rich sulphur center which is easily oxidizable. There seems to be no report on the oxidation aspects of tetrakis(pyridine)silver dichromate (TPSD). Therefore, in continuation of our earlier work by halochromates, we report here the kinetics of oxidation of DL-methionine (Met) by tetrakis(pyridine)silver dichromate in dimethyl sulphoxide (DMSO) as solvent. A suitable mechanism has also been proposed.

\section{EXPERIMENTAL}

Tetrakis(pyridine)silver dichromate was prepared by the reported method ${ }^{2}$ and its purity was checked by an iodometric method. Methionine (Merck) was used as supplied. Due to non-aqueous nature of the solvent, toluene- $p$-sulphonic acid $(\mathrm{TsOH})$ was used as a source of hydrogen ions. Other solvents were purified by the usual methods ${ }^{9}$.

Product analysis: Product analysis was carried out under kinetic conditions. The oxidation of methionine by tetrakis(pyridine)silver dichromate resulted in the formation of corresponding sulphoxide, which was determined by the reported method $^{10}$. The yield of sulphoxide was $94 \pm 3 \%$. The oxidation state of chromium in completely reduced reaction mixtures, as determined iodometrically, was +4 .

Kinetic measurements: The pseudo-first order conditions were attained by maintaining a large excess $(\times 15$ or more $)$ of the methionine over tetrakis(pyridine)silver dichromate. The solvent was DMSO, unless specified otherwise. The reactions were followed, at constant temperatures $( \pm 0.1 \mathrm{~K})$, by monitoring the decrease in [TPSD] spectrophotometrically at $370 \mathrm{~nm}$. No other reactant or product has any significant absorption at this wavelength. The pseudo-first order rate constant, $\mathrm{k}_{\text {obs }}$, was evaluated from the linear $(r=0.990$ - 0.999) plots of $\log$ [TPSD] against time for up to $80 \%$ reaction. Duplicate kinetic runs showed that the rate constants were reproducible to with in \pm $3 \%$. All experiments, other than those for studying the effect of hydrogen ions, were carried out in the absence of $\mathrm{TsOH}$. The second order rate constant, $\mathrm{k}_{2}$, was evaluated from the relation $\mathrm{k}_{2}=\mathrm{k}_{\mathrm{obs}} /[\mathrm{Met}]$. Simple and multivariate linear regression analyses were carried out by the least-squares method on a personal computer. 


\section{RESULTS AND DISCUSSION}

Stoichiometry: The oxidation of methionine by tetrakis(pyridine)silver dichromate resulted in the formation of the corresponding sulfoxides. The overall reaction may therefore, be represented as eqn. (1).

$3 \mathrm{Me}-\mathrm{S}-\mathrm{R}+\mathrm{Cr}_{2} \mathrm{O}_{7}^{-2}+8 \mathrm{H}^{+} \longrightarrow \underset{\|}{3 \mathrm{Me}-\mathrm{S}-\mathrm{R}}+4 \mathrm{H}_{2} \mathrm{O}+2 \mathrm{Cr}^{3+}(1)$ where, $\mathrm{R}$ is $\mathrm{CH}_{2} \mathrm{CH}_{2} \mathrm{CH}\left(\mathrm{NH}_{2}\right) \mathrm{COOH}$

Rate laws: The reactions were found to be first order with respect to tetrakis(pyridine)silver dichromate (Fig. 1). In individual kinetic runs, plots of log [TPSD] versus time were linear $\left(r^{2}>0.995\right)$. Further, it was found that the observed rate constant, $\mathrm{k}_{\mathrm{obs}}$, does not depend on the initial concentration of tetrakis (pyridine) silver dichromate. The order with respect to methionine was less than one (Table-1). A plot of $1 / \mathrm{k}_{\text {obs }}$ versus $1 /[\mathrm{Met}]$ was linear with an intercept on the rate ordinate (Fig. 2). Thus Michaelis-Menten type kinetics were observed with respect to Met. This leads to the postulation of following overall mechanism (eqns. 2 and 3) and the rate law (4).

$$
\begin{gathered}
\text { MeSR }+ \text { TPSD } \stackrel{\text { K }}{\rightleftarrows} \text { [Complex] } \\
\text { [Complex }] \stackrel{\mathbf{k}_{2}}{\longrightarrow} \text { Products }
\end{gathered}
$$

Rate $=\mathrm{k}_{2} \mathrm{~K}[\mathrm{MeSR}][\mathrm{TPSD}] /(1+\mathrm{K}[\mathrm{MeSR}])$

The dependence of $\mathrm{k}_{\mathrm{obs}}$ on the concentration of methionine was studied at different temperatures and the values of $\mathrm{K}$ and $\mathrm{k}_{2}$ were evaluated from the double reciprocal plots. The thermodynamic parameters for the complex formation and activation parameters of the disproportionation of the complexes, at 298 $\mathrm{K}$, were calculated from the values of $\mathrm{K}$ and $\mathrm{k}_{2}$ respectively at different temperatures (Tables 2 and 3).

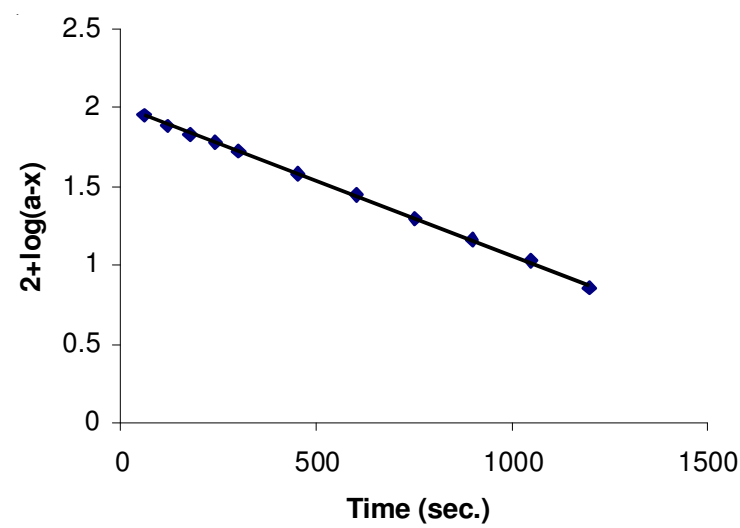

Fig. 1. Oxidation of methionine by tetrakis(pyridine)silver dichromate: A typical kinetic run

Induced polymerization of acrylonitrile/test for free radicals: The oxidation of methionine, in an atmosphere of nitrogen, failed to induce the polymerization of acrylonitrile. Further, the addition of acrylonitrile had no effect on the rate of oxidation (Table-1). Therefore, a one-electron oxidation, giving rise to free radicals, is unlikely. To further confirm the absence of free radicals in the reaction pathway, the reaction was carried out in the presence of $0.05 \mathrm{~mol} \mathrm{dm}^{-3}$ of 2,6-di- $t$ butyl-4-methylphenol (butylated hydroxytoluene or BHT). It was observed that BHT was recovered unchanged, almost quantitatively.

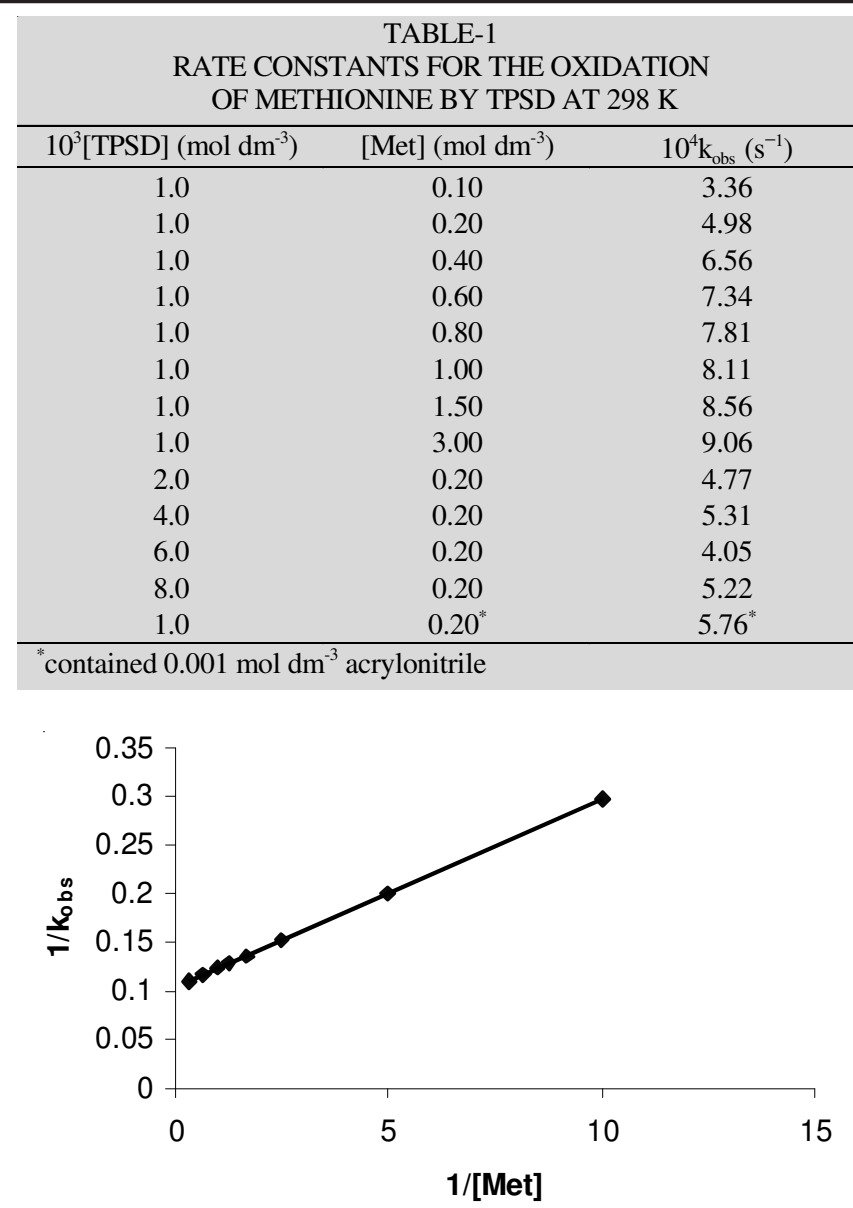

Fig. 2. Oxidation of methionine by tetrakis(pyridine)silver dichromate: A double reciprocal plot

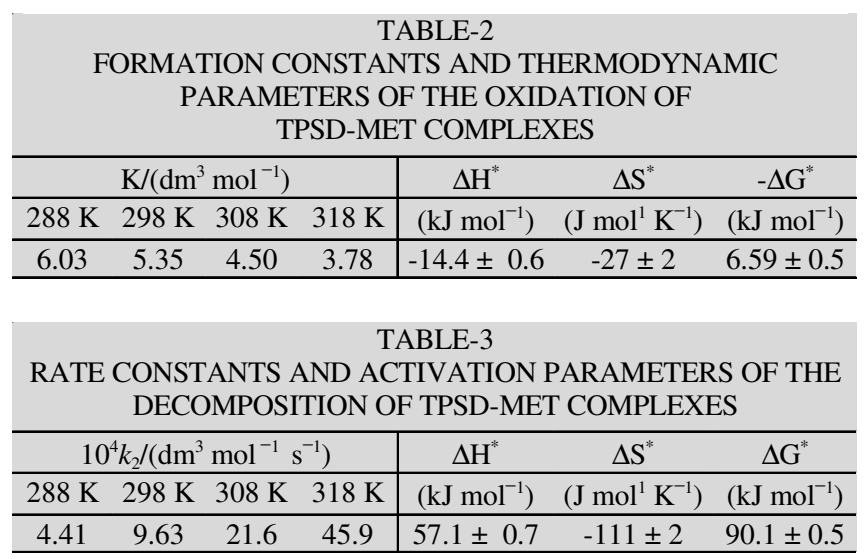

Effect of acidity: The reaction was studied at different acidities by adding varying amount of toluene- $p$-sulphonic acid $(\mathrm{TsOH})$ to the reaction mixtures. The reaction is catalyzed by hydrogen ions (Table-4). The hydrogen-ion dependence has the form $\mathrm{k}_{\mathrm{obs}}=\mathrm{a}+\mathrm{b}\left[\mathrm{H}^{+}\right]$. The values of $\mathrm{a}$ and $\mathrm{b}$ are $3.39 \pm$ $0.04 \times 10^{-4} \mathrm{~s}^{-1}$ and $6.18 \pm 0.06 \times 10^{-4} \mathrm{~mol}^{-1} \mathrm{dm}^{3} \mathrm{~s}^{-1}$ respectively $\left(r^{2}=0.9997\right)$.

Solvent effect: The oxidation of methionine was studied in 19 organic solvents. The choice of solvents was limited due to the solubility of tetrakis(pyridine)silver dichromate and its reaction with primary and secondary alcohols. There was no reaction with the chosen solvents. The kinetics are similar in the all the solvents. The values of $\mathrm{K}$ and $\mathrm{k}_{2}$ are recorded in 
Table-5. A perusal of the data shows that the formation constants do not vary much with the nature of the solvents. However, the rate constants, $\mathrm{k}_{2}$ varied considerably with the solvents. The rate constants for oxidation, $\mathrm{k}_{2}$, in eighteen solvents $\left(\mathrm{CS}_{2}\right.$ was not considered, as the complete range of the solvent parameters was not available) were correlated in terms of the linear solvation energy relationship eqn. (6) of Kamlet et al. ${ }^{11}$

$$
\log \mathrm{k}_{2}=\mathrm{A}_{0}+\mathrm{p} \pi^{*}+\mathrm{b} \beta+\mathrm{a} \alpha
$$

In this equation, $\pi^{*}$ represents the solvent polarity, $\beta$ the hydrogen bond acceptor basicities and $\alpha$ is the hydrogen bond donor acidity. $\mathrm{A}_{0}$ is the intercept term. It may be mentioned here that out of the 18 solvents, 12 have a value of zero for $\alpha$. The results of correlation analyses in terms of eqn. (6), a biparametric equation involving $\pi^{*}$ and $\beta$ and separately with $\pi^{*}$ and $\beta$ are given below.

$$
\begin{aligned}
\log \mathrm{k}_{2}=-4.48+ & 1.59( \pm 0.16) \pi^{*}+0.15( \pm 0.13) \beta+0.29( \pm 0.12) \alpha(7) \\
\mathrm{R}^{2}= & 0.8966 ; \mathrm{sd}=0.14 ; \mathrm{n}=18 ; \psi=0.35 \\
\log \mathrm{k}_{2}= & -4.41+1.49( \pm 0.17) \pi^{*}+0.25( \pm 0.14) \beta \\
\mathrm{R}^{2}= & 0.8568 ; \mathrm{sd}=0.16 ; \mathrm{n}=18 ; \psi=0.40 \\
& \log \mathrm{k}_{2}=-4.35+1.57( \pm 0.18) \pi^{*} \\
\mathrm{r}^{2}= & 0.8260 ; \mathrm{sd}=0.65 ; \mathrm{n}=18 ; \psi=0.43 \\
& \log \mathrm{k}_{2}=-3.54+0.52( \pm 0.33) \beta \\
\mathrm{r}^{2}= & 0.1367 ; \mathrm{sd}=0.39 ; \mathrm{n}=18 ; \psi=0.96
\end{aligned}
$$

\begin{tabular}{|c|c|c|c|c|c|c|}
\hline \multicolumn{7}{|c|}{$\begin{array}{c}\text { TABLE-4 } \\
\text { DEPENDENCE OF THE REACTION RATE ON } \\
\text { HYDROGEN-ION CONCENTRATION }\end{array}$} \\
\hline [Met] $0.10 \mathrm{~mol} \mathrm{dm}^{-3}$ & \multicolumn{4}{|c|}{ [TPSD] $0.001 \mathrm{~mol} \mathrm{dm}^{-3}$} & \multirow{2}{*}{$\begin{array}{c}\text { Temp. } \\
0.80\end{array}$} & \multirow{2}{*}{$\frac{298 \mathrm{~K}}{1.00}$} \\
\hline$[\mathrm{TsOH}] / \mathrm{mol} \mathrm{dm}^{-3}$ & 0.10 & 0.20 & 0.40 & 0.60 & & \\
\hline $10^{4} k_{\mathrm{obs}} / \mathrm{s}^{-1}$ & 3.96 & 4.68 & 5.85 & 7.11 & 8.37 & 9.54 \\
\hline \multicolumn{7}{|c|}{$\begin{array}{c}\text { TABLE-5 } \\
\text { EFFECT OF SOLVENTS ON THE OXIDATION } \\
\text { OF METIONINE BY TPSD AT } 298 \mathrm{~K}\end{array}$} \\
\hline Solvents & & $\mathrm{K}(\mathrm{dr}$ & $\left.{ }^{3} \mathrm{~mol}^{-1}\right)$ & & $10^{5} \mathrm{k}_{2}$ & $\left(\mathrm{~s}^{-1}\right)$ \\
\hline Chloroform & & & 42 & & 77. & \\
\hline 1,2-Dichloroethane & & & 49 & & 87. & \\
\hline Dichloromethane & & & 03 & & 72. & \\
\hline DMSO & & & 35 & & 216 & \\
\hline Acetone & & & 47 & & 63. & \\
\hline DMF & & & 12 & & 117 & \\
\hline Butanone & & & 27 & & 51. & \\
\hline Nitrobenzene & & & 89 & & 95. & \\
\hline Benzene & & & 49 & & 22. & \\
\hline Cyclohexane & & & .58 & & 2.8 & \\
\hline Toluene & & & 65 & & 18. & \\
\hline Acetophenone & & & 29 & & 83.2 & \\
\hline THF & & & 51 & & 33. & \\
\hline$t$-butylalcohol & & & 67 & & 41. & \\
\hline 1,4-Dioxane & & & .85 & & 38. & \\
\hline 1,2-Dimethoxyethane & & & 89 & & 22. & \\
\hline $\mathrm{CS}_{2}$ & & & .04 & & 11.2 & \\
\hline Acetic acid & & & 95 & & 45. & \\
\hline Ethyl acetate & & & .36 & & 30. & \\
\hline
\end{tabular}

Here $\mathrm{n}$ is the number of data points and $\psi$ is the Exner's statistical parameter ${ }^{12}$

Kamlet's ${ }^{11}$ triparametric equation explains $\mathrm{ca} .89 \%$ of the effect of solvent on the oxidation. However, by Exner's ${ }^{13}$ criterion the correlation is not even satisfactory ( $c f$. eqn. 7). The major contribution is of solvent polarity. It alone accounted for $c a .83$ $\%$ of the data. Both $\beta$ and $\alpha$ play relatively minor roles.
The data on the solvent effect were analyzed in terms of Swain's equation ${ }^{13}$ of cation- and anion-solvating concept of the solvents as well.

$$
\log \mathrm{k}_{2}=\mathrm{aA}+\mathrm{bB}+\mathrm{C}
$$

Here $\mathrm{A}$ represents the anion-solvating power of the solvent and $\mathrm{B}$ the cation- solvating power. $\mathrm{C}$ is the intercept term. (A $+\mathrm{B})$ is postulated to represent the solvent polarity. The rates in different solvents were analyzed in terms of eqn. (11), separately with $\mathrm{A}$ and $\mathrm{B}$ and with $(\mathrm{A}+\mathrm{B})$.

$$
\begin{aligned}
\log \mathrm{k}_{2}= & 1.19( \pm 0.04) \mathrm{A}+1.45( \pm 0.03) \mathrm{B}-3.65 \\
\mathrm{R}^{2}= & 0.9960 ; \mathrm{sd}=0.03 ; \mathrm{n}=19 ; \psi=0.07 \\
& \log \mathrm{k}_{2}=0.99( \pm 0.48) \mathrm{A}-2.65 \\
\mathrm{r}^{2}= & 0.2013 ; \mathrm{sd}=0.50 ; \mathrm{n}=19 ; \psi=0.92 \\
& \log \mathrm{k}_{2}=1.36( \pm 0.21) \mathrm{B}-3.26 \\
\mathrm{r}^{2}= & 0.7054 ; \mathrm{sd}=0.24 ; \mathrm{n}=19 ; \psi=0.56 \\
& \log \mathrm{k}_{2}=1.37 \pm 0.04(\mathrm{~A}+\mathrm{B})-3.64 \\
\mathrm{r}^{2}= & 0.9867 ; \mathrm{sd}=0.50 ; \mathrm{n}=19 ; \mathrm{y}=0.12
\end{aligned}
$$

The rates of oxidation of methionine in different solvents show an excellent correlation with Swain's equation with both the cation- and anion-solvating powers playing significant roles, though the contribution of the cation-solvation is slightly more than that of the anion-solvation. The solvent polarity, represented by $(\mathrm{A}+\mathrm{B})$, also accounted for $c a .99 \%$ of the data. However, the correlations individually with $\mathrm{A}$ and $\mathrm{B}$ were poor. In view of the fact that solvent polarity is able to account for $c a .98 \%$ of the data, an attempt was made to correlate the rate with the relative permittivity of the solvent. However, a plot of $\log \mathrm{k}_{2}$ against the inverse of the relative permittivity is not linear $\left(r^{2}=0.4958 ; s d=0.31 ; \psi=0.73\right)$.

The observed solvent effect points to a transition state more polar than the reactant state. Further, the formation of a dipolar transition state, similar to those of $\mathrm{S}_{\mathrm{N}} 2$ reactions, is indicated by the major role of both anion- and cation-solvating powers. However, the solvent effect may also be explained assuming that the oxidant and the intermediate complex exist as ion-pair in non-polar solvent like cyclohexane and be considerably dissociated in more polar solvents.

\section{Mechanism}

In view of the absence of any effect of radical scavenger, acrylonitrile, on the reaction rate and recovery of unchanged $\mathrm{BHT}$, it is unlikely that a one-electron oxidation giving rise to free radicals, is operative in this oxidation reaction. The observed Michaelis-Menten type of kinetics observed with respect to methionine, suggests the formation of 1:1 complex of tetrakis(pyridine)silver dichromate and Met in a rapid pre-equilibrium (Scheme-I). With present set of data, it is difficult to state the definite nature of the intermediate complex. The experimental results can be accounted for in terms of electrophilic attack of methionine-sulphur at the metal via an intermediate complex. Transfer of an unshared pair of electrons to an empty d orbital of the metal resulted in the formation of a coordinate bond. The formation of intermediate is likely to undergo a further rapid reaction in which the incipient.

It is of interest to compare here the mode of oxidation of methionine by pyridinium fluorochromate $(\mathrm{PFC})^{14}$, pyridinium chlorochromate $(\mathrm{PCC})^{15}$, pyridinium bromochromate $(\mathrm{PBC})^{16}$ and tetrakis(pyridine)silver dichromate. The oxidation by PFC and $\mathrm{PBC}$ presented a similar kinetic picture, i.e. the reactions 


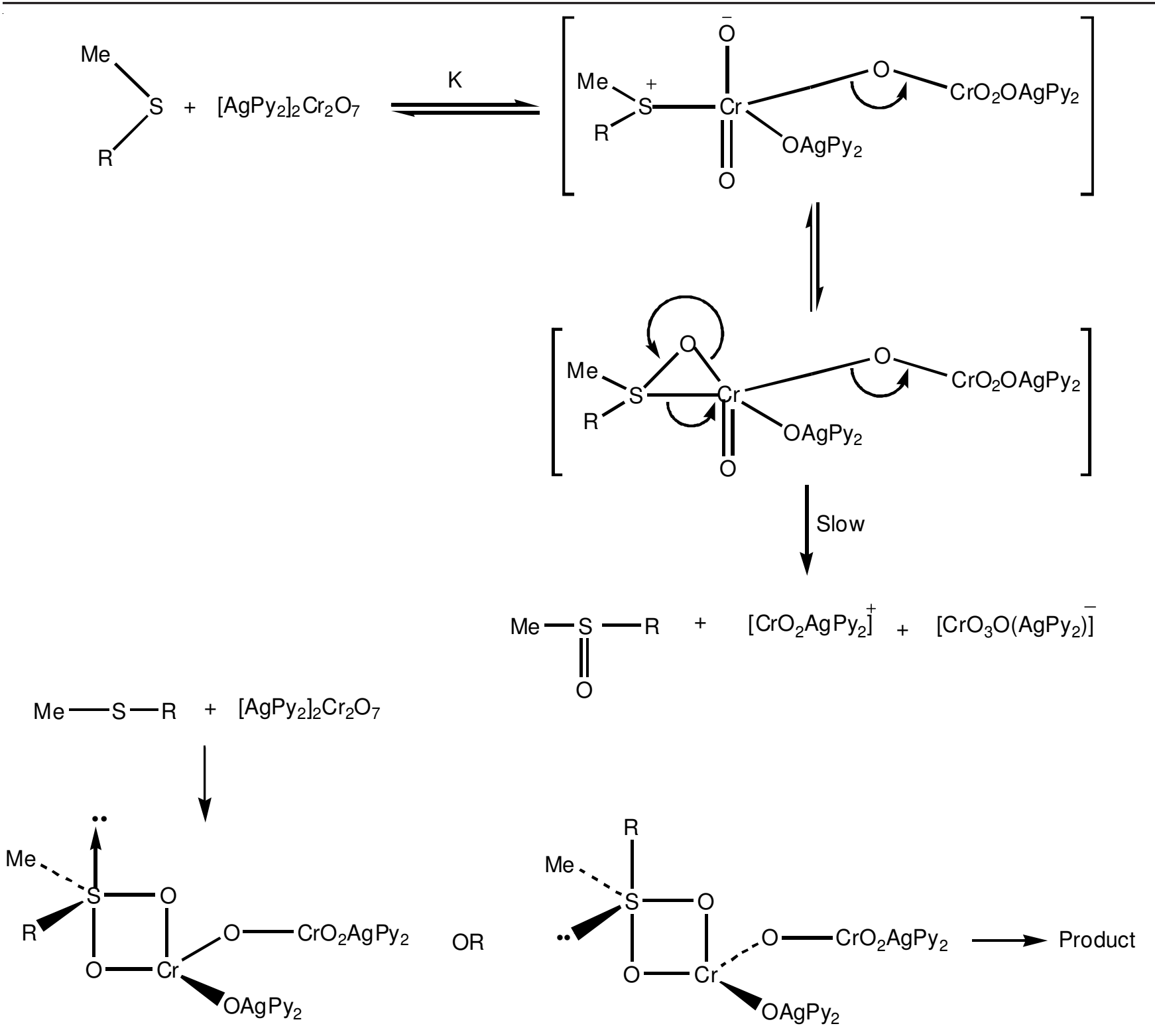

Scheme-I

are of first order with respect to the reductants. While in the oxidation by PCC and tetrakis(pyridine)silver dichromate, Michaelis-Menten type kinetics was observed with respect to the reductants. It is possible that the values of the formation constants for the reductant-PFC/PBC complexes are very low. This resulted in the observation of second-order kinetics. No explanation of the difference is available presently. Solvent effects and the dependence of the hydrogen ions are of similar nature in all these reactions, for which essentially similar mechanisms have been proposed.

\section{ACKNOWLEDGEMENTS}

Thanks are due to the UGC, New Delhi for financial support as BSR, One Time Grant No. F.4-10/2010(BSR) dated 07.03.2012 and to Prof. K.K. Banerji for critical suggestions.

\section{REFERENCES}

1. M.K. Mahanti and K.K. Banerji, J. Indian Chem. Soc., 79, 31 (2002)

2. H. Firouzabadi, A. Sardarian and H. Giaribi, Synth. Communn., 14, 89 (1984).
3. P. Swami, D. Yajurvedi, P. Mishra and P.K. Sharma, Int. J. Chem. Kinet., 42, 50 (2010)

4. K. Vadera, D. Yajurvedi, P. Purohit, P. Mishra and P.K. Sharma, Prog. React. Kinet. Mech., 35, 265 (2010).

5. D. Sharma, P. Panchariya, K. Vadera and P.K. Sharma, J. Sulfur Chem., 32, 315 (2011).

6. D. Sharma, P. Panchariya, S. Vyas, L. Kotai and P.K. Sharma, Int. J. Chem., 1, 29 (2012).

7. D.S. Mahadevappa, S. Ananda, N.M.M. Gouda and K.S. Rangappa, J. Chem. Soc., Perkin Trans. II, 39 (1985).

8. S. Mittal, V. Sharma and K.K. Banerji, J. Chem. Res. (S), 264 (1986).

9. D.D. Perrin, W.L. Armarego and D.R. Perrin, Purification of Organic Compounds, Pergamon, Oxford (1966).

10. J. Mitchell, Org. Anal. Intersci. New York, 1, 375 (1953).

11. M.J. Kamlet, J.L.M. Abboud, M.H. Abraham and R.W. Taft, J. Org. Chem., 48, 2877 (1983).

12. O. Exner, Coll. Czech. Chem. Commun., 38, 411 (1973).

13. C.G. Swain, M.S. Swain, A.L. Powel and S. Alunni, J. Am. Chem. Soc., 105, 502 (1983).

14. V. Sharma, P.K. Sharma and K.K. Banerji, J. Chem. Res. (S), 290 (1996).

15. V. Sharma, P.K. Sharma and K.K. Banerji, J. Indian Chem. Soc., 74, 607 (1997).

16. V. Sharma, P.K. Sharma and K.K. Banerji, Indian J. Chem., 36A, 418 (1997). 